\title{
Risk of Squamous Cell Carcinoma and Adenocarcinoma of the Lung in Relation to Lifetime Filter Cigarette Smoking
}

\author{
Steven D. Stellman, Ph.D., M.P.H. ${ }^{1}$ \\ Joshua E. Muscat, M.P.H. ${ }^{1}$ \\ Seth Thompson, Ph.D. ${ }^{1}$ \\ Dietrich Hoffmann, Ph.D. ${ }^{2}$ \\ Ernst L. Wynder, M.D. ${ }^{1}$ \\ ${ }^{1}$ Division of Epidemiology, American Health \\ Foundation, New York, New York. \\ ${ }^{2}$ Division of Cancer Etiology and Prevention, Amer- \\ ican Health Foundation, Valhalla, New York.
}

Supported by USPHS Grants CA-32617, CA68384, CA-29580, and CA-17613 from the National Cancer Institute.

The authors express their gratitude to Marion Moore and Anna Mondora, field supervisors, to Ilse Hoffmann and Pat Lamb for expert editorial assistance, and to the following individuals and institutions: Elliot Strong, M.D., Newton Morton, M.D., Susan Harlap, M.D., Zuo-Feng Zhang, M.D., Ph.D., and Marianne Berwick, Ph.D., of Memorial Sloan-Kettering Cancer Center, New York, New York; Ronald H. Blum, M.D., of New York University Medical Center, New York, New York; Alfred I. Neugut, M.D., Ph.D., of Columbia University School of Public Health, New York, New York; Philip Witorsch, M.D., of George Washington University Medical Center, Washington, DC; Edward Garrity, Jr., M.D., of Loyola University Hospital, Chicago, Illinois; John Sharp, M.D., of Hines, Illinois; Christine Johnson, Ph.D., of Henry Ford Hospital, Detroit, Michigan; Kanti Rai, M.D., and Marc Citron, M.D., of Long Island Jewish Medical Center, New Hyde Park, New York; Linga Ragu, M.D., of Nassau County Medical Center, East Meadow, New York; James Colberg, M.D., of Thomas Jefferson University Hospital, Philadelphia, Pennsylvania; and Paul Stolley, M.D., of the Hospital of the University of Pennsylvania, Philadelphia, Pennsylvania.

Address for reprints: Steven D. Stellman, Ph.D., M.P.H., American Health Foundation, 320 East 43rd Street, New York, NY 10017.

Received October 16, 1996; revisions received January 2, 1997, and March 26, 1997; accepted March 26, 1997.
BACKGROUND. Over the past few decades, the incidence of adenocarcinoma (AC) of the lung increased much more rapidly than that of squamous cell carcinoma (SCC) in men and women. During this time period, filter cigarettes with substantially reduced "tar" and nicotine yields in the smoke came to dominate the market. METHODS. The risk of SCC and AC in lifelong smokers of filter cigarettes relative to lifelong nonfilter cigarette smokers was assessed in a case-control study performed between 1977 and 1995 with 2292 lung carcinoma patients and 1343 hospital controls who were current smokers.

RESULTS. Odds ratios (OR) for SCC in male and female subjects who had smoked filter cigarettes exclusively during their lives were slightly reduced relative to lifetime nonfilter cigarette smokers in men $(\mathrm{OR}=0.8 ; 95 \%$ confidence interval $[\mathrm{CI}]$, $0.5-1.2$ ), and significantly reduced in women ( $\mathrm{OR}=0.4 ; 95 \% \mathrm{CI}, 0.2-0.8$ ). No reduction in risk was observed for $\mathrm{AC}$ of the lung in men or women.

CONCLUSIONS. Evidence that the increasing predominance of AC over SCC may be due in part to the reduced risk of SCC (but not AC) associated with lifelong filter cigarette smoking is strongest in women; for men, further studies that include larger numbers of lifetime filter smokers are needed to confirm this finding. A lack of protection against AC from low yield filter cigarettes may result from smokers' "compensating" with deeper and more frequent inhalation, thereby increasing delivery of carcinogens to the peripheral lung. The smoke of modern cigarettes also contains higher concentrations of nitrosamines that primarily produce AC. Cancer 1997;80:382-8. (C) 1997 American Cancer Society.

KEYWORDS: lung neoplasms, cigarette smoking, filters, epidemiology, nitrosamines.

M ost of the carcinogens in tobacco smoke reside in the "tar." Since midcentury, the sales-weighted average yield of "tar" declined in the U.S. by approximately $60 \% .^{2}$ According to standardized machine smoking of cigarettes used by the Federal Trade Commission (FTC) to determine the smoke yields of nicotine and "tar" for all brands of cigarettes manufactured in the U.S., the sales-weighted average yields per cigarette until the mid-1960s were in the range of 1.5-2.7 $\mathrm{mg}$ of nicotine and 22-35 mg of "tar." For the most recent 15 -year period, the FTC reported sales-weighted average nicotine and "tar" yields of $0.90-0.95 \mathrm{mg}$ and $12-14 \mathrm{mg}$, respectively. ${ }^{2}$ Today, approximately $25 \%$ of all cigarettes consumed in the U.S. deliver $\leq 0.8$ mg nicotine, and approximately $50 \%$ of cigarettes yield $0.9-1.2 \mathrm{mg}$ of nicotine, whereas the remaining $25 \%$ of brands deliver $\geq 1.2 \mathrm{mg}$ of nicotine. ${ }^{3,4}$

The lower "tar" emissions have been primarily accomplished by utilizing efficient filter tips and highly porous cigarette paper, and by changing the composition of the tobacco blend. Bioassays in labora- 
tory animals conducted during the 1960s and 1970s showed that "tars" of contemporaneously smoked cigarettes had lower carcinogenic activity per gram than earlier cigarettes. ${ }^{5-7}$ Therefore, it was anticipated that the risk of lung carcinoma in smokers of cigarettes with lower "tar" yields would eventually decline relative to risk in smokers of medium or high "tar" brands.

Indeed, reports from the authors' group in $1970,{ }^{8}$ $1976,{ }^{9} 1977,{ }^{10}$ and $1979,{ }^{11}$ as well from other investigators, ${ }^{12-15}$ confirmed that smokers who switched from nonfilter to filter cigarettes had lower lung carcinoma risks compared with those who continued to smoke nonfilter cigarettes. The earlier studies were based on patient populations whose lifetime smoking histories were dominated by nonfilter cigarettes that had significantly higher "tar" emissions than those commonly smoked during recent decades. ${ }^{13}$ However, studies of lung carcinoma patients diagnosed during the past 10-15 years have failed to consistently show a "protective" effect of filters. ${ }^{16-19}$ That the incidence of adenocarcinoma (AC) has been increasing much more rapidly than that of squamous cell carcinoma (SCC) in men and women in the U.S. ${ }^{20}$ even while "tar" and nicotine yields were declining, suggests the need to examine the risk for lung carcinoma by histologic type in relation to long term use of nonfilter and filter cigarettes.

\section{MATERIALS AND METHODS}

This study used data collected from a multicenter hospital-based case-control study of risk factors for lung carcinoma that was initiated in 1977. The methodology has been previously described in detail. ${ }^{10,21}$ In brief, after a consent form approved by the local Institutional Review Board was signed, patients with newly diagnosed lung carcinoma were interviewed by trained personnel in New York and in other U.S. cities. Structured questionnaires were used to obtain detailed smoking histories and data on other lifestyle habits. A complete history of each patient's smoking habits was taken that included the name of each brand and the years during which it was smoked. The histologic types of lung carcinoma were obtained from surgical pathology reports or cytologic findings. The control patients were admitted to the same hospitals for conditions unrelated to cigarette smoking. A frequency matching procedure was based on the case patient's age ( \pm 5 years), gender, hospital, and the date of admission ( \pm 2 months).

Cigarette type was characterized according to whether subjects smoked nonfilter cigarettes exclusively, had switched from smoking nonfilter to filter cigarettes, or had smoked filter cigarettes exclusively. ${ }^{11}$ There were no patients who switched from smoking filter to nonfilter cigarettes. This categorization was chosen because throughout the past 40 years, with few exceptions, filter cigarette brands have had lower levels of "tar" and nicotine than nonfilter brands. This has remained consistent, even as the sales-weighted average "tar" and nicotine levels of both types of cigarettes gradually declined over the years. ${ }^{2}$ Therefore, categorizing cigarettes as filter or nonfilter brands is tantamount to qualitatively dichotomizing by "tar"/ nicotine yield.

Odds ratios (ORs) associated with smoking filter cigarettes were calculated using unconditional logistic regression, adjusting for age, education, and number of cigarettes smoked per day, in separate strata of gender and histologic type of tumor. For these calculations, the reference group was composed of lifetime smokers of nonfilter cigarettes.

Because OR estimates for the two histologic outcomes were based on a common set of control patients, it is inappropriate to use confidence intervals to test whether the ORs for persons with the same filter usage history (e.g., lifetime filter cigarette smokers) differ by histologic type. Wald's chi-square statistic was used to test differences between the regression parameters, utilizing the variance-covariance matrix obtained from a polytomous logistic regression model. $^{22}$

\section{RESULTS}

Between 1977 and 1995, a total of 1442 male and 850 female lung carcinoma patients with SCC or AC who were current smokers were interviewed, along with 876 male and 467 female controls who were also current smokers (Table 1). The ratio of AC to SCC was approximately 1:1 among the males and 2:1 among the females. The proportion of males who smoked filter cigarettes exclusively was $8.5 \%$ of SCC cases, $12.4 \%$ of AC cases, and $13.9 \%$ of controls. Prevalence of lifetime filter cigarette smoking among women was $20.3 \%$ of SCC cases, $27.8 \%$ of AC cases, and $33.8 \%$ of controls.

Histologic type was strongly associated with age and less strongly with education. AC occurred nearly twice as frequently as SCC among both men and women younger than age 45 years who were current smokers, compared with current smokers in older age groups; $11.2 \%$ of the men with AC were diagnosed before age 45 years compared with $6.6 \%$ of men with SCC $(\mathrm{OR}=1.8 ; P<0.01)$ and $12.5 \%$ of women with AC were younger than age 45 years compared with $7.6 \%$ of women with SCC (OR $=1.8 ; P<0.05)$.

Individuals with AC had on average slightly more years of education than those with SCC (12.6 years vs. 11.9 years for men; 12.5 years vs. 12.1 years for women). There were no differences in the distribution of these lung carcinoma cell types between African American and white subjects, and there were no differ- 
TABLE 1

Distribution of Lung Carcinoma Cases and Controls According to Gender, Histologic Type of Carcinoma, and Lifetime Filter Cigarette Smoking. Current Smokers only. American Health Foundation, 1977-1995. (Number of Subjects in Parentheses.)

\begin{tabular}{llll}
\hline & Squamous cell carcinoma & Adenocarcinoma & Controls \\
\hline Males & $(730)$ & $(712)$ & \\
& & Percent & \\
& & 12.4 & \\
Lifetime filter & 8.5 & 68.7 & 13.9 \\
Switched from nonfilter to filter & 69.7 & 19.0 & \\
Lifetime nonfilter & 21.8 & & \\
& & $(569)$ & \\
Females & $(281)$ & 27.8 & \\
Lifetime filter & 20.3 & 66.6 & $(467)$ \\
Switched from nonfilter to filter & 68.0 & 5.6 & 33.8 \\
Lifetime nonfilter & 11.7 & & 59.7 \\
\hline
\end{tabular}

TABLE 2

Average Age and Smoking Characteristics of Study Subjects by Gender, Filter Cigarette Usage, and Histology. Current Smokers only. American Health Foundation, 1977-1995.

\begin{tabular}{|c|c|c|c|c|c|c|c|}
\hline & \multirow[b]{2}{*}{ Filter usage } & \multicolumn{3}{|c|}{ Males } & \multicolumn{3}{|c|}{ Females } \\
\hline & & $\begin{array}{l}\text { Squamous cell } \\
\text { carcinoma }\end{array}$ & Adenocarcinoma & Controls & $\begin{array}{l}\text { Squamous cell } \\
\text { carcinoma }\end{array}$ & Adenocarcinoma & Controls \\
\hline \multirow[t]{3}{*}{ Average age (yrs) at diagnosis } & LF & 48.6 & 49.4 & 46.2 & 52.8 & 50.6 & 51.8 \\
\hline & SW & 59.4 & 58.0 & 58.1 & 60.7 & 58.8 & 57.9 \\
\hline & $\mathrm{NF}$ & 60.3 & 57.7 & 56.8 & 61.6 & 59.8 & 58.8 \\
\hline \multirow[t]{3}{*}{ Average age (yrs) began smoking } & LF & 17.7 & 18.9 & 21.0 & 19.8 & 19.8 & 23.3 \\
\hline & SW & 16.4 & 16.4 & 17.2 & 18.2 & 18.1 & 19.2 \\
\hline & NF & 15.9 & 16.0 & 16.4 & 18.2 & 18.8 & 21.2 \\
\hline \multirow[t]{3}{*}{ Average no. cigarettes smoked per day } & LF & 32.8 & 27.8 & 22.8 & 27.1 & 27.8 & 18.8 \\
\hline & SW & 34.4 & 33.6 & 26.0 & 30.8 & 28.3 & 21.8 \\
\hline & NF & 33.3 & 33.9 & 26.6 & 28.9 & 26.6 & 19.9 \\
\hline \multirow[t]{3}{*}{ Average no. years smoked cigarettes } & LF & 30.5 & 29.4 & 24.2 & 32.7 & 30.4 & 27.4 \\
\hline & SW & 42.6 & 40.9 & 39.8 & 42.0 & 40.3 & 37.6 \\
\hline & NF & 44.2 & 41.3 & 40.1 & 43.2 & 41.5 & 37.5 \\
\hline
\end{tabular}

LF: lifetime filter; SW: switched from nonfilter to filter; NF: lifetime nonfilter.

ences in urban versus rural residence; $55 \%$ of both male and female cases with lung carcinoma of either cell type and 55\% of controls had lived in large metropolitan areas ( $>250,000$ persons) for most of their adult lives.

\section{Characteristics of Current Cigarette Smokers}

Lifetime filter cigarette smokers (LF), both men and women, were substantially younger than either lifetime nonfilter cigarette smokers (NF) or controls (Table 2). This age difference was reflected in substantially shorter duration of smoking: 13.7 years less for men and 10.5 years less for women with SCC who were LF smokers compared with NF smokers of the same gender. Generally, the NF smokers began to smoke at earlier ages than did the LF smokers (4.6 years earlier for male controls, 2.1 years earlier for female controls).

The ORs and 95\% confidence intervals (CI) according to duration of filter cigarette smoking for the three filter usage categories are presented in Table 3. ORs are adjusted for age, education, and number of cigarettes smoked per day. Among current smokers, the critical factor in this table was the extent, if any, to which LF smokers may be at lower risk compared with NF smokers, and specifically whether this effect differs by histologic type of lung carcinoma. The risk of SCC was slightly lower among LF smokers for men $(\mathrm{OR}=0.8 ; 95 \% \mathrm{CI}, 0.5-1.2)$ and significantly lower for 
TABLE 3

Adjusted $^{\mathrm{a}}$ Odds Ratios for Squamous Cell Carcinoma and Adenocarcinoma of the Lung among Current Cigarette Smokers, by Lifetime Filter/ Nonfilter Cigarette Consumption. American Health Foundation, 1977-1995.

Males

\begin{tabular}{|c|c|c|c|c|c|c|c|c|}
\hline \multirow[b]{2}{*}{ No. of subjects } & \multirow[b]{2}{*}{$\begin{array}{l}\text { Controls } \\
876 \\
(\%)\end{array}$} & \multicolumn{3}{|c|}{ Squamous cell carcinoma } & \multicolumn{3}{|c|}{ Adenocarcinoma } & \multirow[b]{2}{*}{ Chi-square $^{b}$} \\
\hline & & $\begin{array}{l}\text { Cases } \\
730 \\
(\%)\end{array}$ & OR & $95 \% \mathrm{CI}$ & $\begin{array}{l}\text { Cases } \\
712 \\
(\%)\end{array}$ & OR & $95 \% \mathrm{CI}$ & \\
\hline Lifetime nonfilter smoker & 18.8 & 21.8 & 1.0 & & 19.0 & 1.0 & & \\
\hline Switched & 67.2 & 69.7 & 0.9 & $0.7-1.2$ & 68.7 & 1.0 & $0.8-1.3$ & 0.4 \\
\hline Lifetime filter smoker & 13.9 & 8.5 & 0.8 & $0.5-1.2$ & 12.4 & 1.0 & $0.7-1.5$ & 1.0 \\
\hline
\end{tabular}

Females

\begin{tabular}{|c|c|c|c|c|c|c|c|c|}
\hline \multirow[b]{2}{*}{ No. of subjects } & \multirow[b]{2}{*}{$\begin{array}{l}\text { Controls } \\
467 \\
(\%)\end{array}$} & \multicolumn{3}{|c|}{ Squamous cell carcinoma } & \multicolumn{3}{|c|}{ Adenocarcinoma } & \multirow[b]{2}{*}{ Chi-square $^{b}$} \\
\hline & & $\begin{array}{l}\text { Cases } \\
281 \\
(\%)\end{array}$ & OR & $95 \% \mathrm{CI}$ & $\begin{array}{l}\text { Cases } \\
569 \\
(\%)\end{array}$ & OR & $95 \% \mathrm{CI}$ & \\
\hline Lifetime nonfilter smoker & 6.4 & 11.7 & 1.0 & & 5.6 & 1.0 & & \\
\hline Switched & 59.7 & 68.0 & 0.6 & $0.3-0.99$ & 66.6 & 1.2 & $0.7-2.0$ & $7.0^{\mathrm{c}}$ \\
\hline Lifetime filter smoker & 33.8 & 20.3 & 0.4 & $0.2-0.8$ & 27.8 & 0.9 & $0.5-1.7$ & $7.6^{\mathrm{c}}$ \\
\hline
\end{tabular}

OR: odds ratio; CI: confidence interval.

${ }^{\text {a } A d j u s t e d ~ f o r ~ a g e ~(c o n t i n u o u s), ~ e d u c a t i o n ~(t h r e e ~ c a t e g o r i e s), ~ a n d ~ n u m b e r ~ o f ~ c i g a r e t t e s ~ p e r ~ d a y ~(t h r e e ~ c a t e g o r i e s) . ~}$

${ }^{\mathrm{b}}$ Wald chi-square test for equality of logistic regression coefficients between histologic types.

${ }^{\mathrm{c}} P<0.01$.

women $(\mathrm{OR}=0.4 ; 95 \% \mathrm{CI}, 0.2-0.8)$. ORs for SCC among those who switched from nonfilter to filter cigarettes were intermediate. By contrast, the AC risks were not significantly reduced either for men or for women $(\mathrm{OR}=1.0$ and 0.9 , respectively).

\section{DISCUSSION}

These findings support the hypothesis that the widescale changes in the incidence of SCC and AC are related to changes in the concentration and type of carcinogens in the smoke of manufactured cigarettes. Since approximately 1970 in the U. S., AC as a percent of all lung carcinomas has nearly doubled in males and increased from approximately $25 \%$ to approximately $33 \%$ in women, among whom AC has long been the most commonly diagnosed histologic type. ${ }^{20,23} \mathrm{~A}$ similar shift in histology was recently noted in Switzerland by Levi et al., who theorized that "similar exposure to tobacco-related carcinogens leads to similar rates of histologic type-specific lung carcinoma incidence in males and females." 24

In the authors' earlier studies and those of other groups that were performed through the mid-1980s, lower overall lung carcinoma risks were observed for filter smokers and switchers compared with nonfilter cigarette smokers, and in some studies lung carcinoma risk increased in proportion to the "tar" yield of cigarettes. ${ }^{8-13,15}$ Those earlier reports are consistent with the current findings for SCC, at least in men, because that was the dominant histologic type during that era. The current analysis refines and extends the work of Wynder and Kabat who, a decade ago, characterized the type of cigarette in relation to histologic type of lung tumor. They reported a lower risk of Kreyberg type 1 lung carcinoma (SCC + large cell + oat cell) for filter-only smokers of both genders, but little or no decreased risk for Kreyberg type 2 lung carcinoma (AC + bronchiolar + alveolar cell). ${ }^{19}$ Risks were reported for composite histologic categories because the number of LF smokers in each category was relatively small. Small numbers of NF smokers with AC made it necessary to include short term filter $(<10$ years) smokers with nonfilter smokers in the reference group, which in the current study is composed exclusively of NF smokers. In the current analysis, the percentage of current LF smokers increased from $<8 \%$ for men and $18 \%$ for women in $1977-1980$ to $34 \%$ of male and $49 \%$ of female patients seen in 1991-1995 (Fig. 1).

A strength of this study is that all cases and controls were interviewed in person; no data were obtained from next-of-kin or other surrogates. This is especially important because accurate reports of ciga- 


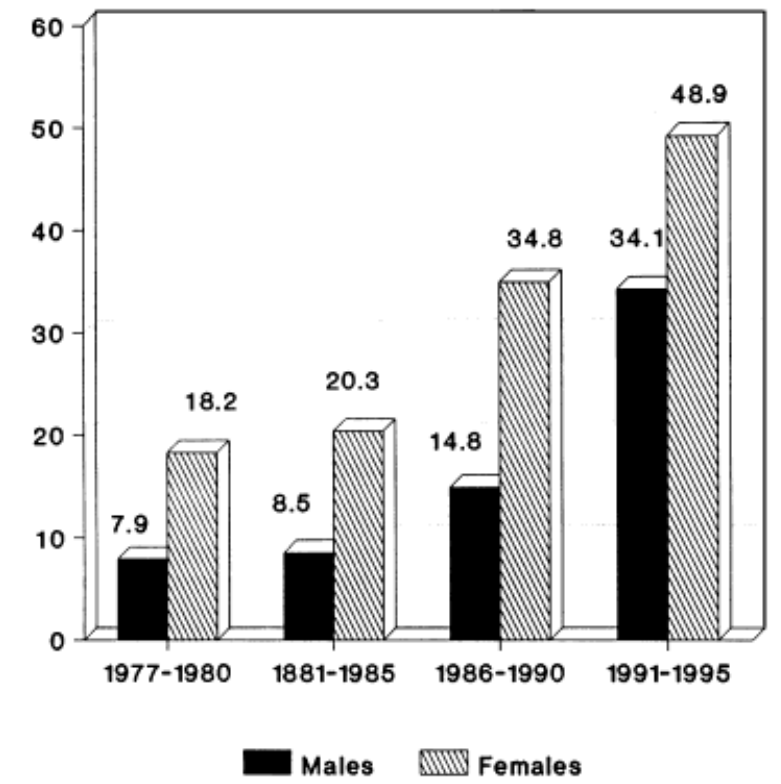

FIGURE 1. Lifetime filter cigarette smokers as a percentage of all current smokers in four time periods by gender. Adapted from American Health Foundation data, 1977-1995.

rette brands and quantity smoked may not always be obtained from relatives. Since 1980, periodic reinterviews with a sample of cases and controls in the authors' study have shown high reliability levels for smoking data. ${ }^{25,26}$ Use of closely supervised, trained interviewers, and rigorous quality control procedures for data management also serve to increase confidence in results. Refusal rates have consistently been $<10 \%$, so that little selection bias is believed to exist. Histologies have been taken from final pathologic reports without reconfirmation; however, the study is restricted to the two principal histologic types of lung carcinoma, for which a high degree of interobserver reproducibility has been reported elsewhere. ${ }^{27}$

A potential limitation in a long term retrospective study such as the current study is that it covers an extended time period (approximately 17 years); the lower mean age of LF smokers compared with current smokers with a history of both nonfilter and filter cigarette usage is a reflection of the fact that younger cohorts of smokers have had more opportunity to be LF smokers.

Such potential time period artifacts are reduced by interviewing controls in the same age strata and time period as the cases, and by adjusting for age in the analyses (which also tends to adjust for duration of smoking). The authors tested the hypotheses that the ORs were homogeneous across 3 time periods (1977-1979, 1980-1985, and 1986-1995); using the method of Breslow and Day ${ }^{28}$; none of these hypotheses were rejected $(P>0.05)$. Nevertheless, the authors noted that ORs for AC among female LF smokers and switchers were two to three times higher in the time period 1980-1985 than in either the earlier or later periods, although these estimates were based on very small numbers of female NF smokers.

Using another approach, the authors tabulated the ratio of AC to SCC cases among patients who were diagnosed only during the most recent time period (1991-1995), according to the calendar year in which they began to smoke cigarettes. This revealed a dramatic increase in the AC:SCC ratio in smokers of both genders (shown in Table 4), which was in full support of the authors' hypothesis. Restriction to recently diagnosed cases minimizes the "generational" problem of comparing risks in smokers from different eras and emphasizes the effect of individuals' early cigarette brand choices, because "starter" brands invariably have had higher FTC-rated smoke yields than brands smoked later in life.

LF smoking was associated with a significant reduction of risk for SCC in women; for men the reduction in SCC, although suggestive, was not statistically significant (Table 3). No reduction in AC risk was observed for either men or women. It should be noted that only $8.5 \%$ of the male SCC cases interviewed to date were LF smokers; therefore, a definitive test of any effect in males must await further accumulation of cases.

Several factors are likely to have contributed to the lack of any observed decreased risk for AC among current LF smokers. First, the lowering of nicotine yields by as much as $60 \%$ (based on machine-smoked, FTC-reported yields for cigarettes ${ }^{3}$ ) during the lifetime of these smokers has led to the phenomenon of compensation. This is a behavioral adjustment by those who smoke low yield and medium yield cigarettes ( $\leq 1.2 \mathrm{mg}$ nicotine). In these cases, the cigarettes are smoked with greater frequency of puff drawing and with greater puff volume, and the smoke is inhaled far more deeply into the lungs ${ }^{29-32}$ to achieve a desired physiologic response to the pharmacoactive nicotine. The authors postulate that such a physiologically conditioned change in smoking behavior has led to an altered deposition pattern of particulate matter within the lungs. The particle size distribution in the smoke that is inhaled from filter cigarettes has shifted toward smaller size aerosols with an average greatest dimension of $0.20 \mu$ (compared with $0.25 \mu$ for the smoke of nonfilter cigarettes ${ }^{33}$ ); it has been estimated that in a long term smoker ( $\geq 3$ years) of high nicotine nonfilter cigarettes the deposition of particles in the upper respiratory tract has its highest density in the bifurcation zone of the tracheobronchial tree ${ }^{34-37}$ However, on deep inhalation of the smoke, the distribution of smoke particles shifts in such a way that nearly $50 \%$ 
TABLE 4

Number of Lung Carcinoma Cases with SCC and AC Diagnosed between 1991-1995, and AC:SCC Ratio

\begin{tabular}{lllllll}
\hline & \multicolumn{2}{c}{ Males } & & & \multicolumn{2}{c}{ Females } \\
\cline { 2 - 4 } $\begin{array}{l}\text { Year of onset of } \\
\text { cigarette } \\
\text { smoking }\end{array}$ & $\begin{array}{l}\text { Squamous cell } \\
\text { carcinoma }\end{array}$ & Adenocarcinoma & AC:SCC & & $\begin{array}{l}\text { Squamous cell } \\
\text { carcinoma }\end{array}$ & Adenocarcinoma \\
\hline & No. & No. & 35 & Ratio & No. & No. \\
1948 and earlier & 41 & 50 & 0.85 & 20 & 41 & Ratio \\
$1949-1959$ & 36 & 45 & 1.39 & 27 & 47 & 2.05 \\
1960 and later & 30 & & 1.50 & 7 & 49 & 7.00 \\
\hline
\end{tabular}

SCC: squamous cell carcinoma; AC: adenocarcinoma.

of the particles are trapped in the alveolar regions of the lungs. ${ }^{37}$ The ratios of SCC to AC along the airways thus correspond roughly to the deposition patterns of smoke particles of different sizes. Furthermore, Yang et al. have noted that the physical distribution of AC parallels the distribution of glandular cells along the surface of the respiratory tract. ${ }^{38}$

The hypothesis that deeper inhalation by smokers of low yield cigarettes is linked to the upward shift in rates of AC relative to SCC also agrees with the observation that lung neoplasms in primary smokers of pipes and cigars, whose smoke inhalation is shallow, are usually SCC arising from the major bronchi. ${ }^{39} \mathrm{Ci}-$ gars and pipes generate alkaline smoke with significant amounts of unprotonated (free) nicotine that is rapidly absorbed through the oral mucosa, thus quickly satisfying nicotine demand without deep inhalation, ${ }^{40}$ so that the smokers inhale little or no smoke from these products.

A second, complementary hypothesis suggests that smoking cigarettes with lower "tar" yields may not reduce one's risk for AC because some of the potential benefit of the lower levels of polynuclear aromatic hydrocarbons (PAH) in the smoke of these cigarettes is offset by the higher levels of organ specific, carcinogenic tobacco specific nitrosamines (TSNAs) in the smoke of modern day cigarettes. ${ }^{41}$ Within the past two decades, 4-(methylnitrosamino)-1-(3-pyridyl)-1butanone (NNK) yield, used as a surrogate measure for total TSNA and whose metabolites can be detected in the urine of smokers, ${ }^{42}$ increased by nearly $75 \%$ from $110 \mathrm{ng}$ per cigarette in 1978 to $191 \mathrm{ng}$ in 1995 in the smoke of U.S. nonfilter cigarettes; similar trends for NNK were observed in the smoke of other cigarettes, including filter cigarettes. By contrast, the percigarette emission of benzo(a)pyrene (BaP) (a surrogate measure for levels of carcinogenic $\mathrm{PAH}$ ) in the smoke of the best-selling U.S. nonfilter cigarette declined from $52 \mathrm{ng}$ in 1965 to $18 \mathrm{ng}$ in $1995 .{ }^{43}$ The authors believe it to be significant, in keeping with differences in histologic types of human lung carci- noma, that $\mathrm{NNK}$ induces primarily adenoma and $\mathrm{AC}$ of the lung in mice, rats, and Syrian golden hamsters, independent of site of application, ${ }^{44}$ whereas intratracheal instillation of $\mathrm{BaP}$ and other carcinogenic $\mathrm{PAH}$ preferentially induces SCC in rats and hamsters. ${ }^{45}$ Workers exposed to aerosols from combustion products with high concentrations of carcinogenic PAH present mainly with SCC. ${ }^{46,47}$ Thus, changes in the population ratio of SCC to AC are consistent with changes in the concentrations of histology specific lung carcinogens in cigarette smoke.

As the number of persons who have smoked low yield cigarettes (e.g., $<10 \mathrm{mg}$ "tar," < $1.0 \mathrm{mg}$ nicotine) for their lifetime continues to grow, and as more of these smokers who exceed the latency associated with smoking such cigarettes develop lung carcinoma, opportunities for evaluating and quantifying the health risks of these newer tobacco products will also increase. Such studies need to be performed on a broad basis because tobacco use continues to be the major cause of preventable cancer mortality in the U.S.

\section{REFERENCES}

1. U.S. Surgeon-General. The health consequences of smoking. The changing cigarette. Washington, DC: U.S. Public Health Service, 1981.

2. Hoffmann D, Hoffmann I. Tobacco consumption and lung cancer. In: Hansen HH, editor. Advances in basic and clinical research. Boston: Kluwer Academic Publications. 1994:142.

3. Federal Trade Commission. Tar, nicotine, and carbon monoxide content of the smoke of 933 varieties of domestic cigarettes. Washington, DC: U.S. Government Printing Office, 1994.

4. Maxwell JC. Maxwell report: U.S., Part II. Marlboro dominates. Tobacco Rep 1996;123(4):19-21.

5. U.S. Dept. of Health Education and Welfare. The Health consequences of smoking ([CDC] 74-8704). Washington, DC: U.S. Department of Health, Education, and Welfare, 1974.

6. Weber KH. Recent changes in tobacco products and their acceptance by the consumer. In: Proceedings of the Sixth International Tobacco Scientific Congress, Tokyo, Japan. CORESTA Information Bulletin 1976; (Special):15-30. 
7. Wynder EL, Hoffmann D. Tobacco and tobacco smoke: studies in experimental carcinogenesis. New York: Academic Press, 1967.

8. Wynder EL, Mabuchi K, Beattie EJ. The epidemiology of lung cancer. JAMA 1970;213:2221-8.

9. Wynder EL, Mushinski M, Stellman SD. The epidemiology of the less harmful cigarette. In: Proceedings 3rd World Conference on Smoking and Health. 1976;1:1-13.

10. Wynder EL, Stellman SD. Comparative epidemiology of tobacco-related cancers. Cancer Res 1977;37:4608-22.

11. Wynder EL, Stellman SD. Impact of long-term filter cigarette usage on lung and larynx cancer risk: a case-control study. J Natl Cancer Inst 1979;62:471-7.

12. Hammond EC, Garfinkel L, Seidman H, Lew EA. "Tar" and nicotine content of cigarette smoke in relation to death rates. Environ Res 1976; 12:263-74.

13. Stellman SD. Cigarette yield and cancer risk: evidence from case-control and prospective studies. In: Zaridze DG, Peto $\mathrm{R}$, editors. Tobacco, a major international health hazard, IARC Scientific Pub. No. 74. Lyon: International Agency for Research on Cancer, 1986:197-209.

14. Lubin JH, Blot WJ, Berrino F, Flamant R, Gillis CR, Kunze $\mathrm{M}$, et al. Patterns of lung cancer risk according to type of cigarette smoked. Int J Cancer 1984;33:569-76.

15. Stellman SD, Garfinkel L. Lung cancer risk is proportional to cigarette tar yield: evidence from a prospective study. Prev Med 1989; 18:518-25.

16. Sidney S, Tekawa IS, Friedman GD. A prospective study of cigarette tar yield and lung cancer. Cancer Causes Control 1993; 4:3-10.

17. Wilcox HB, Schoenberg JB, Mason TJ, Bill JS, Stemhagen A. Smoking and lung cancer: risk as a function of cigarette tar content. Prev Med 1988; 17:263-72.

18. Garfinkel L, Stellman SD. Smoking and lung cancer in women: findings in a prospective study. Cancer Res 1988; 48:6951-5.

19. Wynder EL, Kabat GC. The effect of low-yield cigarette smoking on lung cancer risk. Cancer 1988;62:1233-30.

20. Devesa SS, Shaw GL, Blot WJ. Changing pattern of lung cancer incidence by histological type. Cancer Epidemiol Biomark Prev 1991;1:29-34.

21. Wynder EL, Covey LS. Epidemiologic patterns in lung cancer by histological type. Eur J Cancer Clin Oncol 1987;23:14916.

22. Dubin N, Pasternack BS. Risk assessment for case-control subgroups by polychotomous logistic regression. Am J Epidemiol 1986; 123:1101-17.

23. Patel AR, Obrams GI. Adenocarcinoma of the lung: meeting report. Cancer Epidemiol Biomark Prev 1995;4:175-80.

24. Levi F, Franceschi S, La Vecchia C, Randimbison L, Te V-C. Lung carcinoma trends by histologic type in Vaud and Neuchâtel, Switzerland, 1974-1994. Cancer 1997;79:906-14.

25. Morabia A, Moore M, Wynder EL. Reproducibility of food frequency measurements and inferences from a case-control study. Epidemiology 1990; 1:305-10.

26. Kabat GC, Stellman SD, Wynder EL. Relation between exposure to environmental tobacco smoke and lung cancer in lifetime nonsmokers. Am J Epidemiol 1995; 142:141-8.

27. Campobasso O, Andrion A, Ribpotta M, Ronco G. The value of the 1981 WHO histological classification to inter-observer reproducibility and changing pattern of lung cancer. Int $J$ Cancer 1993;53:205-8.

28. Breslow NE, Day NE. Statistical methods in cancer research. Volume 1. The analysis of case-control studies. IARC Scien- tific Pub. No. 32. Lyon: International Agency for Research on Cancer, 1980.

29. Herning RI, Jones RT, Bachman J, Mines AH. Puff volume increases when low-nicotine cigarettes are smoked. $\mathrm{Br}$ Med J (Clin Res Ed) 1981;283:187-9.

30. Wynder EL, Goodman MT, Hoffmann D. Demographic aspects of the low-yield cigarette: considerations in the evaluation of health risk. J Natl Cancer Inst 1984;72:817-22.

31. Wynder EL, Hoffmann D. Smoking and lung cancer: scientific challenges and opportunities. Cancer Res 1994;54:528495.

32. Djordjevic MV, Fan J, Ferguson S, Hoffmann D. Self-regulation of smoking intensity. Smoke yields of the low-nicotine, low-'tar' cigarettes. Carcinogenesis 1995; 16:2015-21.

33. Keith $\mathrm{CH}$, Derrick JC. Measurement of the particle size distribution and concentration of cigarette smoke by the "conifuge." J Colloid Sci 1960; 15:340-56.

34. Schmähl D, Consbruch U, Druckrey H. Fluoreszensmessungen am Zigarettenrauch. Arzneimittelforschung 1954; 4:71-5.

35. Ermala P, Holsti LR, Distribution and absorption of tobacco tar in the organs of the respiratory tract. Cancer 1955; 8:6738.

36. Wynder EL, Hoffmann D. Some practical aspects of the smoking-cancer problem. N Engl J Med 1960;262:540-5.

37. Hollander W, Stöber W. Aerosols of smoke, respiratory physiology and deposition. Arch Toxicol Suppl 1986; 9:74-87.

38. Yang CP, Gallagher RP, Weiss NS, Band PR, Thomas DB, Russell DA. Differences in incidence rates of cancers of the respiratory tract by anatomic subsite and histologic type: an etiologic implication. J Natl Cancer Inst 1989;81:1828-31.

39. Higgins ITT, Mahan CM, Wynder EL. Lung cancer among cigar and pipe smokers. Prev Med 1988;17:116-28.

40. Armitage AK, Turner DM. Absorption of nicotine in cigarette and cigar smoke through the oral mucosa. Nature 1970; 226:1231-2.

41. Hecht SS, Hoffmann D. Tobacco-specific nitrosamines, an important group of carcinogens in tobacco and tobacco smoke. Carcinogenesis 1988;9:875-84.

42. Carmella SG, Akerkar SA, Richie JP Jr., Hecht SS. Intraindividual and interindividual differences in metabolites of the tobacco-specific lung carcinogen 4-(methylnitrosamino)-1(3-pyridyl)-1-butanone (NNK) in smokers' urine. Cancer Epidemiol Biomark Prev 1995;4:635-42.

43. Hoffmann D, Hoffmann I. The changing cigarette: 19501995. J Toxicol Environ Health 1997;50:307-64.

44. Hoffmann D, Brunnemann KD, Prokopczyk B, Djordjevic M. Tobacco-specific N-nitrosamines and areca-derived Nnitrosamines: chemistry, biochemistry, carcinogenicity, and relevance to humans. J Toxicol Environ Health 1994;41:152.

45. Davis BR, Whitehead JK, Gill ME, Lee PN, Butterworth AD, Roe FJC. Response of rat lung to inhaled tobacco smoke with or without prior exposure to 3,4-benzpyrene (BP) given by intratracheal instillation. Br J Cancer 1975;31:469-84.

46. International Agency for Research on Cancer. Polynuclear aromatic compounds. Part 2. Carbon blacks, mineral oils and some nitroarenes. IARC monographs on the evaluation of the carcinogenic risk of chemicals to humans. Volume 33. Lyon: International Agency for Research on Cancer, 1984

47. International Agency for Research on Cancer. Polynuclear aromatic compounds. Part 3. Industrial exposures in aluminum production, coal gasification, coke production, and iron and steel founding. IARC monographs on the evaluation of the carcinogenic risk of chemicals to humans. Volume 34. Lyon: International Agency for Research on Cancer, 1984. 